\title{
Fundamental Factors Determining Laboratory Sintering Results
}

\author{
C. E. LOO and D. J. WONG
}

Newcastle Technology Centre, BHP Billiton Technology, PO Box 188, Wallsend, NSW 2287 Australia.

( Received on August 27, 2004; accepted on November 5, 2004)

\begin{abstract}
The main purpose of sinter pot studies is to quantify the common indicators of performance viz., mix moisture, productivity, coke rate and sinter quality. For three ore blends-containing 50 mass\% pisolite ore and up to 30 mass\% Marra Mamba ore-sintering studies were carried out using two laboratory sintering techniques, and the fundamental factors influencing these key indicators were accurately quantified. The study supports previous findings that pre- and post-ignition airflow rates provide invaluable information on flame front properties, sintering time and sinter strength. Sintering results obtained for the two techniques were very different because of differences in flame front properties. Clearly, a good understanding of the influence of flame front temperature, sintering energy requirements, airflow rate and bed thermal capacity on heat transfer and bed airflow resistance is necessary to explain the fundamental sintering behaviour of ore blends. To help quantify these links, the factors governing airflow through a sintering bed and the drivers causing the flame front to descend down a bed were also presented from a theoretical perspective. As expected, both theory and test results show that post-ignition airflow rate, the level of coke in the granulated mix, and endothermic reactions such as calcination were very important factors influencing flame front resistance and, therefore, the sintering performance of ore blends.
\end{abstract}

KEY WORDS: sinter pot test; goethitic ore blends; productivity; coke rate; sinter strength.

\section{Introduction}

Studies involving a laboratory pilot plant-commonly termed a sinter pot-are widely used to assess the sintering performance of iron ore blends. The current standard pot test procedure adopted at the Newcastle Technology Centre (NTC) of BHPB Billiton uses around $60 \mathrm{~kg}$ of granulated sinter feed. Sufficient sinter is produced for the standard bulk characterisation tests viz., tumble strength, reduction degradation, reducibility and softening/melting. From information gathered during sintering, calculations can also be carried out to determine sintering productivity, coke rate and yield.

In recent times, the capability of the NTC sinter pot has been extended to include the accurate determination of airflow rates before and after bed ignition. ${ }^{1,2)}$ To obtain these measurements sintering procedures had to be modified, in particular to reduce the ingress of air around the pot wall. This was achieved by introducing an annular layer of fine sand between the granulated bed and the pot wall. It is the authors' view that this new sintering technique gives improved test repeatability and should be adopted more widely.

The main purpose of this paper is to study the fundamental factors influencing sintering results from both the conventional and modified techniques. The blends chosen for study contained 50 mass $\%$ pisolite ore and varying levels of Marra Mamba ore, and they represent the current and future ore blends of Asian steel mills.

\section{Comparison of Laboratory and Plant Results}

Many years ago, a program was carried out to assess how well laboratory results compare against an existing plant operation. To this end, a large amount of granulated sinter feed was collected just before the sinter strand feed hopper over two periods - in the morning and afternoon of the same day. The samples were divided into small amounts, placed into plastic bags, sealed and carefully transported back to the laboratories for sinter pot studies. At the same time samples of sinter were also collected for characterisation from a conveyor belt close to the blast furnace. The performance of the sinter plant was also carefully monitored during the day of sampling and averaged productivity values obtained.

At the laboratories, the granulated mixes were sintered using two cylindrical pots of 0.05 and $0.09 \mathrm{~m}^{2}$ cross sectional area, and also in a rectangular unit with a grate area of $0.2 \mathrm{~m}^{2}$. Single tests were carried out on the morning and afternoon samples in each pot/unit. Only the original unmodified technique i.e., without sealing at the pot wall, was used to process these samples. After sintering, the products were stabilized by dropping from $2 \mathrm{~m}$ four times. There was very little difference between the sintering results for materials collected in the two periods. The collected plant sinter was also evaluated for strength, RDI, reducibility and mineral/phase compositions, as was all the pot sinters. Table 1 shows a comparison of the plant and pot results. From Table 1 it is clear that productivity from the largest laboratory unit compared best with plant data. For the smaller units productivity was much higher than plant values. 
Table 1. Comparison of plant and pot results for the same plant granulated sample.

\begin{tabular}{||l|c|c|c|c|}
\hline & Plant & \multicolumn{3}{|c|}{ Laboratory unit grate area $\left.\mathbf{m}^{2}\right)$} \\
\hline \multirow{2}{*}{ Sintering performance } & & 0.2 & 0.09 & 0.05 \\
\hline Productivity (t/m $\left.{ }^{2} . \mathrm{d}\right)$ & & & & \\
\hline Return fines balance* & $\begin{array}{c}29 \text { (average } \\
\text { for day of } \\
\text { sampling) }\end{array}$ & 32 & 37 & 34 \\
\hline Sinter bulk properties & $\begin{array}{c}1.00 \\
\text { (assumed) }\end{array}$ & 0.98 & 1.12 & 1.15 \\
\hline $\begin{array}{l}\text { ISO tumble index } \\
\text { (mass \%+6.4 mm) }\end{array}$ & & & & \\
\hline RDI (mass \% -2.8 mm) & 71 & 69 & 65 & 65 \\
\hline RI (\%R) & 28 & 28 & 28 & 29 \\
\hline & 60 & 60 & 59 & 61 \\
Sinter mineralogy (vol.\%) & & & & \\
\hline Magnetite & 19 & 20 & 22 & 22 \\
\hline Primary hematite & 23 & 24 & 21 & 24 \\
\hline Secondary hematite & 13 & 11 & 11 & 9 \\
\hline SFCA & 33 & 32 & 33 & 33 \\
\hline Glass & 5 & 5 & 5 & 4 \\
\hline Dicalcium silicate & 5 & 6 & 6 & 7 \\
\hline Quartz & 2 & 2 & 2 & 1 \\
\hline
\end{tabular}

* at that time the plant was running at a return fines of 24 mass percent on ore basis, and values greater than unity indicate that the level of fines generated was greater than the level of fines in the sinter mix.

Return fines generation was also much higher for the smaller sized units, resulting in return fines balances (ratio of return fines mass generated by stabilization to the mass of return fines in the sinter mix) of greater than 1.10.

The plant sinters were much stronger possibly because they had been stabilised under more severe conditions or because they had been subjected to higher sintering temperatures. Although the two sinter pots were lagged on the outside with kaowool, while the wall of the large unit was refractory lined on the inside, it is to be expected that heat loss under laboratory conditions would be higher simply because of the larger wall area per unit mass of sinter. The other possibly more important factor causing increased heat loss from the pot is the ingress of air at the pot walls, which led to increased heat loss from the bed and, hence, a lower flame front temperature. This is discussed in detail in the later sections of this paper. The magnetite content or $\mathrm{FeO}$ of the sinters were very similar suggesting similar maximum sintering temperatures but then this parameter is also influenced by factors such as cooling rate, ${ }^{3,4)}$ which is higher for the pot tests.

The current NTC standard pot test procedure uses the $0.09 \mathrm{~m}^{2}$ unit. The results of Table 1 would suggest that tumble strengths of around 65 mass\% plus $6.4 \mathrm{~mm}$ are adequate for stabilised pot sinters. Generally, sinter plants these days operate at productivities greater than $30 \mathrm{t} / \mathrm{m}^{2} \cdot \mathrm{d}$, so laboratory values in excess of $37 \mathrm{t} / \mathrm{m}^{2} \cdot \mathrm{d}$ should also be acceptable.

\section{Laboratory Procedures}

This section is aimed at clarifying our terminologies, presenting our approach to the formulation of test programs, and summarising the recent changes ${ }^{1,2)}$ in our test procedure.

\subsection{Terminology}

In this paper, detailed sintering results are presented. Full definitions of the terms used in sinter pot testing together with the indicators of sintering performance are given below.

Sinter Mix Moisture-expressed as a mass percent of the granulated sinter mix, as charged into the sinter pot. As the same granulation drum was used in all the tests and granulation time was kept constant at $10 \mathrm{~min}$, sinter mix moisture should be the main parameter affecting granulation efficiency. It is, however, important to note that two similar ore blends can have slightly different bed permeability for the same sinter mix moisture if there are differences in the inherent moistures of the blend components. $\left.{ }^{4}\right)$

Coke in Mix - expressed as a mass percent on ore basis. It is important to emphasise that two similar ore blends could have the same mass percent coke in the sinter mix but the mass percent coke per unit mass of sinter mix will be different if they contain dissimilar levels of return sinter fines, limestone, or $\mathrm{MgO}$-bearing minerals. The mix containing more return fines will have less coke in a unit mass of sinter mix, and this will result in lower flame front temperature.

Green and Sintering Bed Airflow - these are determined using a hot wire anemometer located in a hood above the sinter bed and expressed in cubic metres per hour. ${ }^{1,2)}$

Return Fines Level-for these tests, sinter return fines is the mass percent minus $5 \mathrm{~mm}$ material. As for coke, this parameter is also expressed as mass percent on ore basis. For a fully balanced operation, the mass ratio of return fines added into the sinter mix to the mass percent minus $5 \mathrm{~mm}$ sinter generated after stabilisation is unity. Pot tests are only accepted if the obtained returns fines balance is between 0.95 and 1.05 .

Yield-is the ratio of mass plus $5 \mathrm{~mm}$ sinter generated after stabilisation to the total mass of sinter produced in the test, expressed as a percent. For balanced tests, return fine level in the sinter mix should be inversely proportional to yield.

Sintering Time - the time from the start of bed ignition to the waste gas reaching peak temperature.

Productivity - is expressed as tonnes of acceptable sinter (mass percent $+5 \mathrm{~mm}$ material) produced per square meter of the pot per day. Productivity decreases if sintering time increases or if yield decreases.

Coke Rate-is expressed as kg of coke required to produce a tonne of acceptable sinter. This parameter is dependent on coke in the mix, the mass of return fines and other additives added into the ore blend, and yield.

Tumble Index - is the strength of the stabilized sinter determined using ISO 3271-1995.

\subsection{Program Philosophy}

All NTC test programs are directed towards achieving defined outcomes. In considering potential ore blends, the first aim is to determine if these blends can be sintered to match the performance of a base blend. Sintering conditions used usually involve a fixed ignition time, granulation time and stabilisation procedure. Parameters such as bed height, ignition and sintering suctions are altered to match values used at the plant under consideration. Coke level in the sinter mix and the amount of water added during granulation are variables in the tests, as is the level of return sinter fines in the granulated mix. These variables are altered 
to obtain productivity and sinter strength values matching those determined earlier from tests on a base blend. In addition, for tests to be acceptable they must be 'in return fines balance' - meaning that the mass of return fines added into the sinter mix must be almost equal to the mass of return fines generated after the sintered bed is stabilised. Once it has been established that the new blend can be sintered to match the base case, further studies can be carried out to determine if the performance for the new blend can be improved.

The three test variables - mix moisture, coke level and return fines level-are often interdependent because altering one can affect another e.g., increasing the level of return fines decreases the coke level of the sinter mix and will also change the granulation behaviour of the mix and, therefore, mix moisture requirements. It is most likely that there is not a unique combination of these three variables, which would give an acceptable balance of return fines operation and produce sinter at comparable productivity and strength. For this reason, sinter pot results may not always demonstrate progressive, consistent trends - for example, increasing the level of an ore in a certain blend might not give a gradual change in a parameter such as sinter strength if the return fines level is increased mid-way to bring the tests into return fines balance. When clear definitive trends are not obtained there is a need to understand the underlying reasons; otherwise, pot test results are just experimental outcomes that are sometimes unreliable, but the cause of which cannot be explained.

\subsection{New Technique}

In a recent test program, aimed at measuring airflow rate through a sintering bed to determine green and sintering bed permeabilities, ${ }^{2)}$ an annular layer of fine sand was placed at the inner steel wall of the cylindrical pot to reduce the ingress of air. Without an annular layer, airflow measurements would not be accurate because of the ingress of air at the wall before ignition and during sintering.

Results indicate that the use of an annular layer of fines is imperative if meaningful airflow measurements reflecting the permeability of the sintering bed are to be obtained. Following on from our earlier program, ${ }^{2)}$ which was aimed only at measuring airflow rates before and after bed ignition, this study will include the quantification of sintering performance and sinter strength. This can only be determined if the cylindrical sintered cake formed is stabilized and processed. Initial tests showed that sand particles used to seal the pot wall degraded on heating, causing a significant amount of ultra-fines to be formed during sintering. From a health perspective, sand is not an acceptable material because degraded sand particles attached to the sintered bed become airborne when the bed is stabilised by dropping from $2 \mathrm{~m}$. For this program, fine iron ore (minus $0.25 \mathrm{~mm}$ ) was used instead of sand.

A decision was also made to carry out comparative studies without the fine ore annular layer and these, termed conventional tests, are indicated by an additional suffix (C). Tests that incorporate an annular fines layer are simply termed the new or modified technique.
Table 2. Details of ore blends studied.

\begin{tabular}{|l|c|c|c|}
\hline & Blend P & Blend M20 & Blend M30 \\
\hline Australian hematite & 15 & 9 & 6 \\
\hline Pisolite ore & 50 & 50 & 50 \\
\hline Brazilian hematite & 35 & 21 & 14 \\
\hline Marra Mamba ore & 0 & 20 & 30 \\
\hline & & & \\
\hline Fe (total) & 57.9 & 57.8 & 57.8 \\
\hline $\mathbf{S i O}_{2}$ & 4.99 & 4.90 & 4.90 \\
\hline $\mathbf{A l}_{\mathbf{2}} \mathbf{O}_{3}$ & 1.77 & 1.79 & 1.70 \\
\hline $\mathbf{M g O}^{\text {Basicity }}$ & 1.50 & 1.50 & 1.50 \\
\hline MgO from serpentine (mass \%) & 1.80 & 1.80 & $1.80^{*}$ \\
\hline
\end{tabular}

* A different, higher-grade limestone was used to source the $\mathrm{CaO}$

** Increased use of dolomite to replace serpentine could have an adverse effect on sintering

Table 3. Summary of base pot test sintering conditions.

\begin{tabular}{|l|l|}
\hline Parameter & \\
\hline Granulation time & $10 \mathrm{~min}$ \\
\hline Grate area & $0.09 \mathrm{~m}^{2}$ \\
\hline Bed height & $\begin{array}{l}550 \mathrm{~mm} \text { (includes } 30 \mathrm{~mm} \\
\text { hearth layer) }\end{array}$ \\
\hline Ignition temperature & $1200^{\circ} \mathrm{C}$ \\
\hline Ignition suction & $6 \mathrm{kPa}$ \\
\hline Ignition time & $90 \mathrm{~s}$ \\
\hline Sintering suction & $16 \mathrm{kPa}$ \\
\hline Cooling & Downdraft at $16 \mathrm{kPa}$ \\
\hline Sinter stabilization & 4 drops from $2 \mathrm{~m}$ \\
\hline
\end{tabular}

\subsection{Current Program}

Details of the high goethite ore blends considered in this paper are shown in Table 2. Blend $\mathrm{P}$ contains 50 mass $\%$ pisolite ore, while Blend M20 contains 50 mass\% pisolite ore and 20 mass\% Marra Mamba ore. To match the sinter chemical composition of Blend $\mathrm{P}$ the dolomite to serpentine ratio of Blend $\mathrm{M} 20$ had to be altered. The increased level of dolomite in Blend M20 could have an adverse affect on sintering performance. ${ }^{5)}$ Blend M30 has 10 mass\% more of Marra Mamba ore compared to Blend M20 but a limestone of lower gangue was used. This meant that a similar sinter chemical composition to Blend $\mathrm{P}$ could be obtained without altering the dolomite to serpentine ratio. Details of the base sintering conditions used in the pot test work are shown in Table 3.

In all these tests, sintering performance was quantified by: green and sintering bed airflow rates, sintering time, productivity, coke rate, sinter yield and sinter tumble index. Green and sintering airflow rates are not normally considered in sinter pot test studies, but these parameters have been studied in some detail at these laboratories recently because of their impact on flame front speed. ${ }^{1,2)}$ The factors that influence sintering time have also been considered in some detail recently. ${ }^{6)}$ Further progress has been made in understanding both of these areas and their importance in sintering is discussed in the next section.

\section{Theoretical Considerations}

\subsection{Airflow Rates}

The factors influencing green and sintering airflow rates are summarised in Fig. 1. A consideration of the Ergun equation shows that for turbulent flow green bed permeability is a function of two parameters controlling the physical structure of the bed-voidage and effective particle diame- 


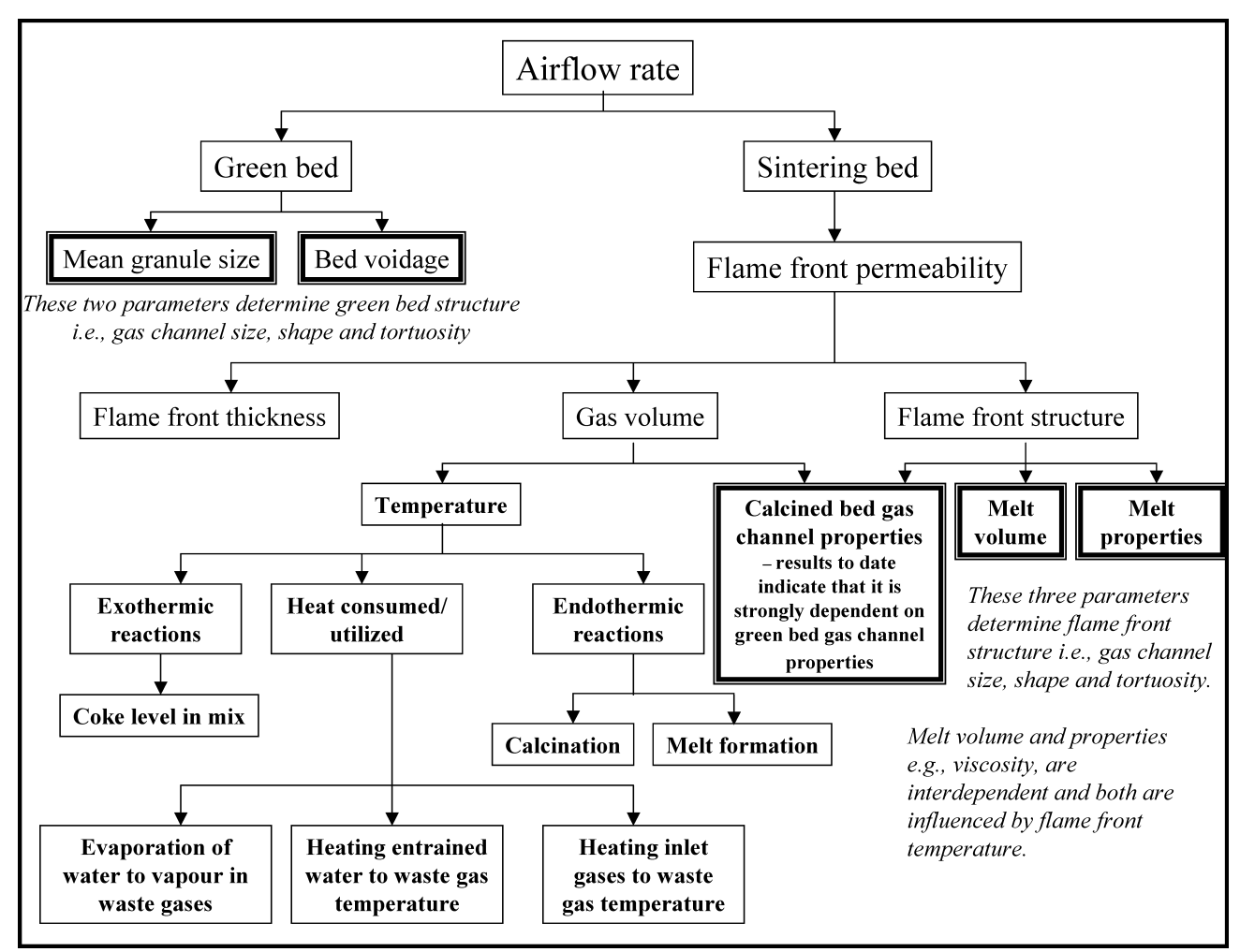

Fig. 1. Factors controlling airflow rate through a bed before and after ignition.

ter-and gas density. ${ }^{1,2)}$ These two parameters determine the properties of the gas channels in the bed and, therefore, the ease at which air can be drawn through the bed. For a green bed of fixed cross-sectional area, bed height and applied suction, airflow rate through the bed is solely a function of the bed structure if constant gas density and turbulent conditions are assumed.

For a sintering bed, studies have shown that the permeability of the flame front controls airflow rate. ${ }^{1,2)}$ Theoretical considerations and experimental results indicate that the permeability of the flame front is influenced by its thickness, the velocity of the flowing gases or gas volume, and the physical structure of the flame front (see Fig. 1). There is evidence to indicate that the combustion rate of coke particles can influence the thickness of the flame front. ${ }^{2)}$ Studies have shown that gas velocity in the flame front is strongly dependent on pre-ignition gas velocitybecause of the strong link between the physical structure of the pre- and post-ignition beds - and flame front temperature. ${ }^{2)}$ Increasing coke addition level increases flame front temperature and gas volume, but processes such as calcination, evaporation and melt formation consumes heat and lead to lower flame front temperatures. Using concepts developed for green bed permeability, the important structural properties of the flame front are the size and tortuosity of the gas channels present. These are principally dependent on the structure of the calcined bed and changes that have occurred because of the formation of melt. Results obtained to date ${ }^{2)}$ suggest that large gas channels in the green bed become large gas channels in the flame front, and that changes caused by calcination are negligible. Although studies have shown that flame front structure is independent of melt volume and melt properties, these two parameters are included in Fig. 1 because they could be important for some ore blends.

The formation of melt should increase voidage because melt occupies less space than the original solid iron ore and flux particles - which naturally contain varying amount of intra-particle pores. An extremely important property of melts is that they coalesce, transforming the uniformly packed bed of granules into sinter particles and very large gas channels in the bed. ${ }^{4,7)}$ As a large channel offers less resistance to flow compared a number of smaller channels of the same cross-sectional area, the coalescing behaviour of melts should have an influence flame front permeability. Increasing temperature will result in more melt and greater melt coalesce, which should improve the permeability of the flame front. However, this may not be the final outcome since increasing flame front temperature will increase gas velocity, leading to increased flame front resistance and reduced airflow rates. ${ }^{2)}$

\subsection{Sintering Time}

Based on heat transfer analysis, a hypothesis has been given on what controls flame front speed. ${ }^{6}$ It is assumed that the flame front moves when the thin layer of calcined granules just ahead of the flame front reaches the spontaneous coke combustion temperature, which is around $1000^{\circ} \mathrm{C}$. Based on this hypothesis, the factors influencing flame front speed can be analysed further and Fig. 2 summarises the concepts and relationships between these factors.

Convective heat transfer from the flame front to the thin layer is, of course, extremely important. While heat may flow by conduction and radiation into this layer, only convection causes the net downward directional flow of heat and, therefore, greatly influences the descend of the flame front. Increasing airflow rate will increase the convective 


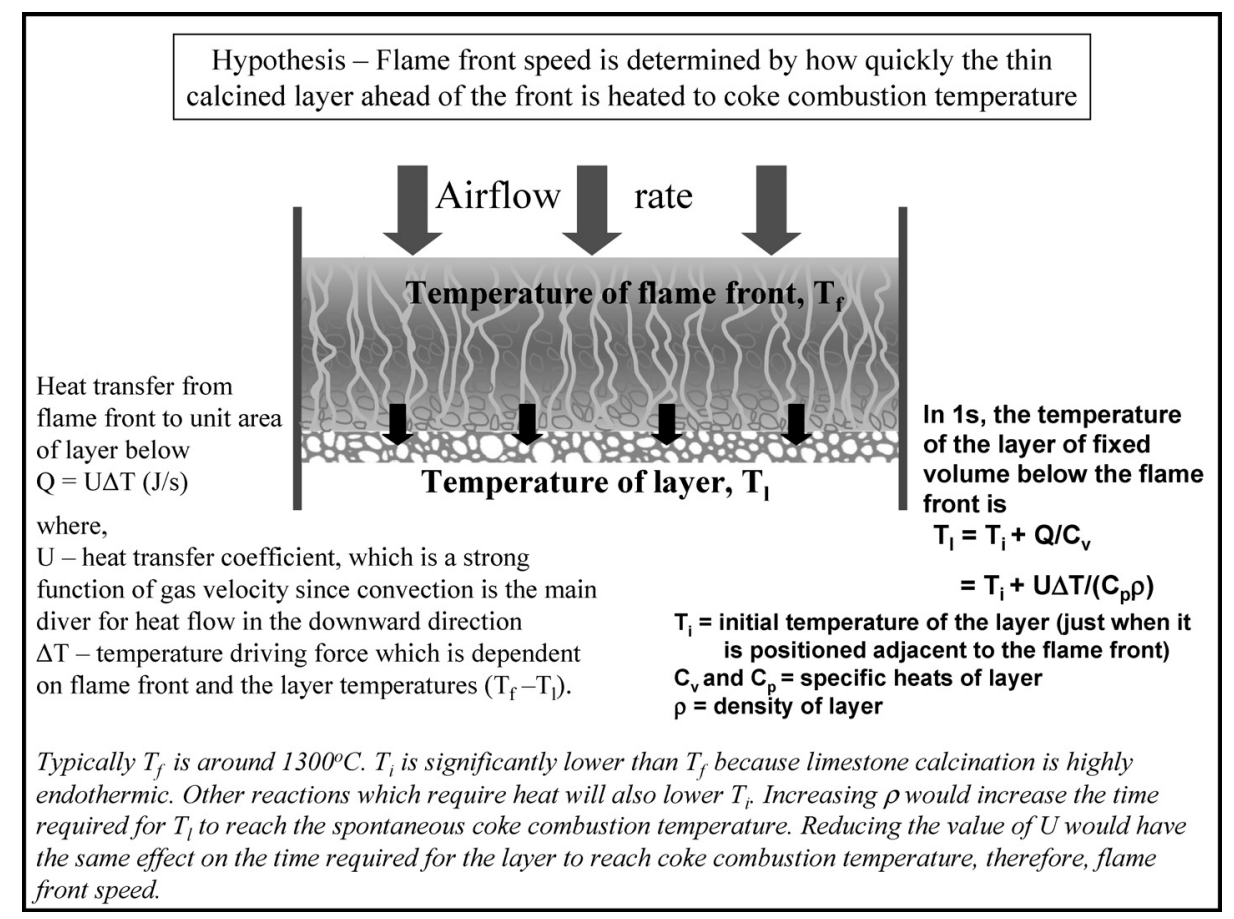

Fig. 2. Factors influencing flame front speed and sintering time.

transfer of heat downwards (i.e. the value of the convective heat transfer coefficient, $U$, in Fig. 2) and increase flame front speed. It is for this reason that such a strong relationship exists in sintering between granulation efficiency and productivity. However, the expected relationship between the convective heat transfer coefficient and airflow rate $(v)$ is not linear: $U$ is typically dependent on $v^{n}$, where $n$ is around $0.8 .^{6)}$ This means that when airflow rate is low increasing $v$ gives very significant increases in flame front speed, but when $v$ is large the benefit of further increasing its value is small. ${ }^{6}$

Increasing the temperature of the flame front will also increase the transfer of heat from the flame front because of a larger $\Delta T$ (Fig. 2). This should have a positive impact on increasing heat transfer from the flame front, but there are other more important considerations. Increasing flame front temperature will greatly increase gas volume and, therefore, gas velocity at the flame front. Earlier studies have shown that the resistance of the flame front to airflow is proportional to gas velocity to the power of three. ${ }^{2)}$ For this reason, increasing flame front temperature will result in decreased airflow rate, leading to reduced heat transfer from the flame front to the thin calcined layer underneath.

While the rate of heat transfer to the layer is important, flame front speed is ultimately determined by the time required for the layer to reach the spontaneous coke combustion temperature. $\left.{ }^{6}\right)$ This means that the thermal properties of the bed also influences sintering time. For beds formed from the same ore blend, flame front speed should only be a function of sintering airflow rate. But if one bed is formed from a blend containing dense ores - hence, more solid material per unit volume of the bed-then for the same sintering bed permeability and airflow rate, flame front speed will decrease because a longer time is required to heat the bed to the spontaneous coke combustion temperature. A mathematical expression of the rate of temperature rise of this layer is given on the right-hand-side of Fig. 2. It is important to note that with denser ores in the mix slowing of the flame front and increasing sintering time may not always have a negative impact on sinter plant productivity because the mass of sinter produced per unit volume of strand is higher.

Figure 2 shows that the other factor that can slow down the flame front speed is $T_{\mathrm{i}}$, the temperature of the layer when it is initially positioned adjacent to the flame front. If the limestone content of a sinter mix is increased, for example, then $T_{\mathrm{i}}$ should be smaller because of increased calcination demands. When this happens flame front speed should decrease because a longer time is required for the layer to reach the spontaneous coke combustion temperature. However, for a fixed value of $Q$, reducing $T_{\mathrm{i}}$ should reduce flame front temperature, $T_{\mathrm{f}}$, improve flame front permeability and increase sintering airflow rate-resulting in a faster sintering time.

\section{Conventional Technique versus New Technique}

The purpose of these tests was to compare sintering results with and without an annular sealing layer. Airflow rate prior to ignition was determined at the sintering suction value of $16 \mathrm{kPa}$. Immediately after igniting the bed under a suction of $6 \mathrm{kPa}$, a hood was placed over the top of the pot and suction was increased to $16 \mathrm{kPa}$. A hot wire anemometer located in the hood gave a continuous measure of airflow through the bed. Details of the procedures have been described. ${ }^{1,2)}$

\subsection{Comparison of Results}

Using the conventional and the new techniques, sintering was carried out on the same ore blend granulated under similar conditions. Results for Blends $\mathrm{P}$ and $\mathrm{P}(\mathrm{C})$ are shown in Fig. 3. There is a slight difference in the mix 


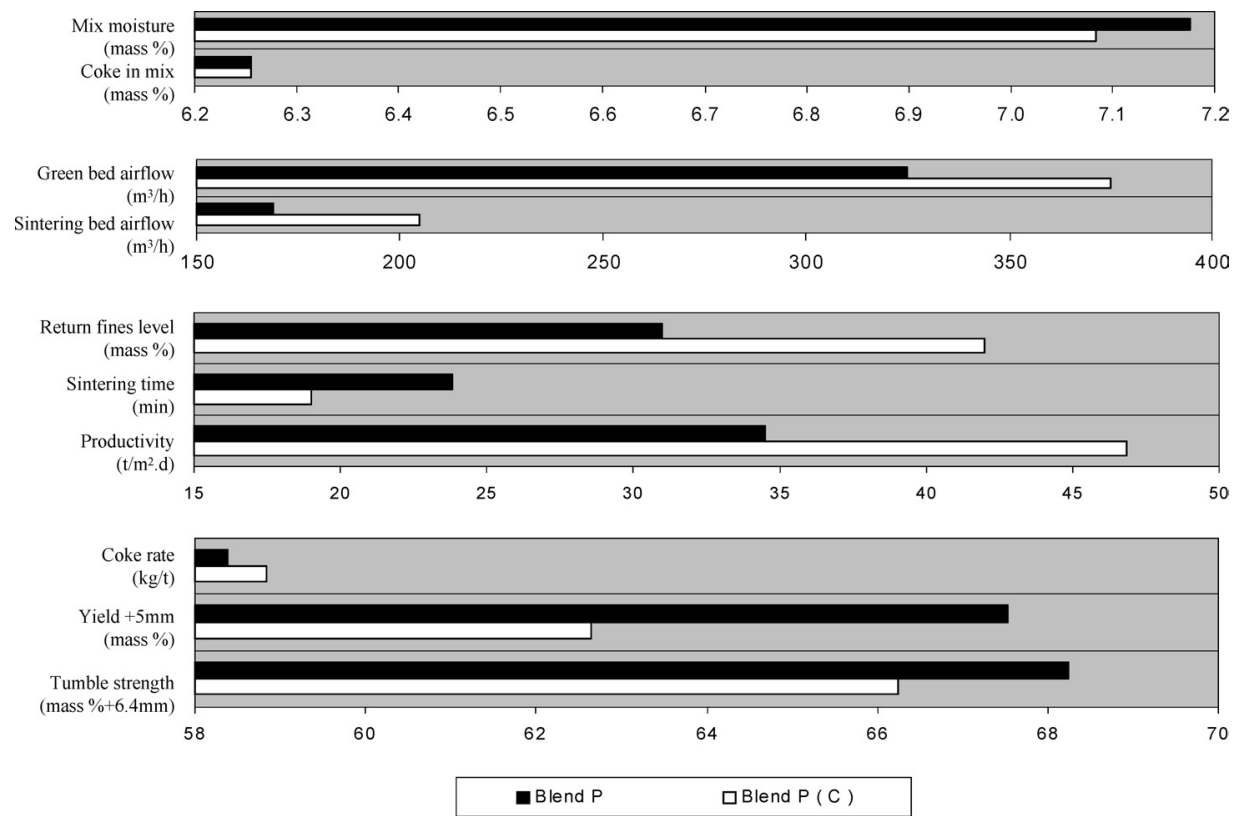

Fig. 3. Comparison of sintering results for Blend $P$ using the conventional method $(C)$ and new method incorporating an annular fines layer.
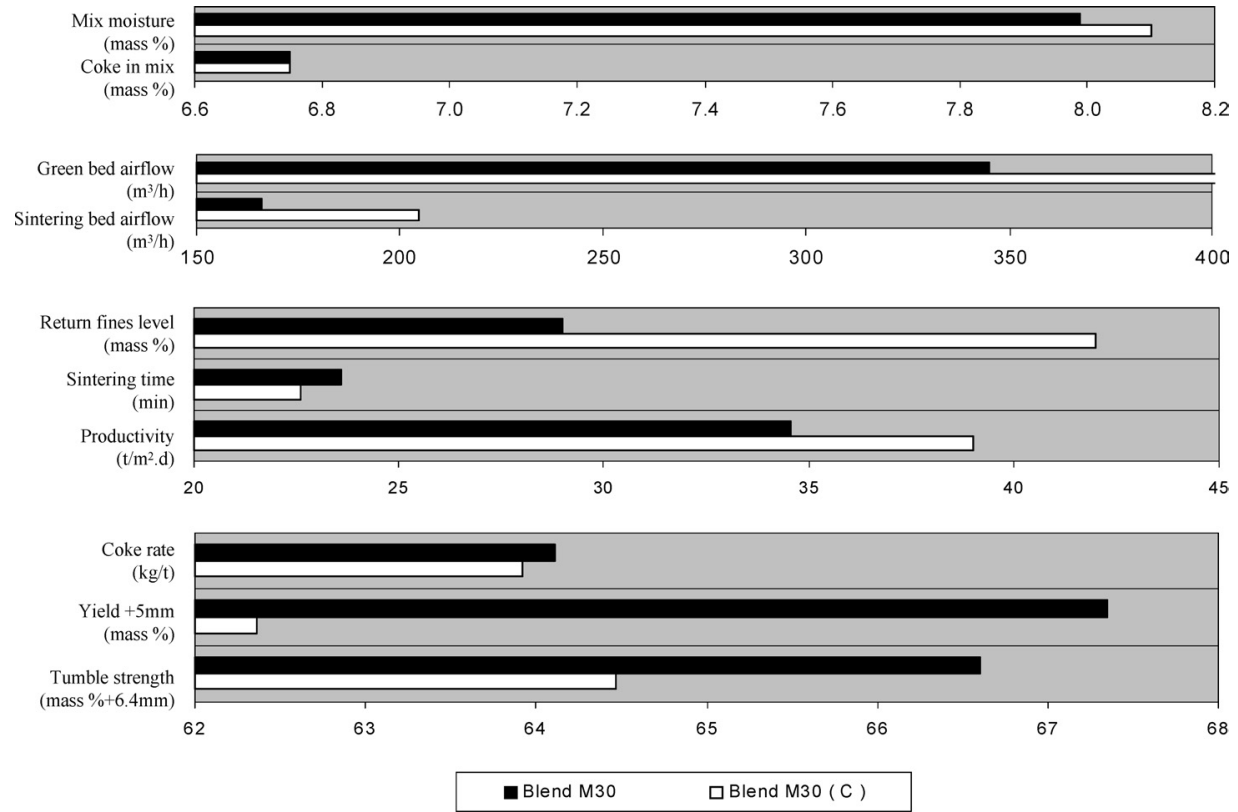

Fig. 4. Comparison of sintering results for Blend M30 using the conventional method (C) and new method incorporating an annular fines layer.

moisture of the two tests, by $0.1 \%$. Even at slightly lower mix moisture the conventional test gave a significantly higher pre- and post-ignition airflow rates. Return fines level was much higher for the conventional technique because material around the pot wall was poorly sintered. Sintering time is very much shorter for the conventional test, but yield is significantly lower. Productivity, which is dependent more on sintering time than yield, is, therefore, much higher for the conventional test. Coke rate is higher for the conventional test, mainly because of reduced yield. Sinter strength, as quantified by tumble index, is lower for the conventional test.

Figure 4 compares the results obtained for Blends M30 and $\mathrm{M} 30(\mathrm{C})$. The trends obtained are very similar to those shown in Fig. 3. Introducing the annular fines layer reduced return fines level, pre- and post-ignition airflow rates and productivity; while sintering time, yield and sinter strength increased. The only difference between Figs. 3 and 4 is the trends in coke rate. As discussed in Section 3.1, the mass percent coke in the sinter mix and yield determines coke rate. For the conventional technique, the mass percent coke in the sinter mix is lower because of the higher level of return fines, but then yield is also lower-which should result a small net change in coke rate compared to the new technique. The relative values of these two terms have resulted in a small decrease in coke rate from Blend $\mathrm{P}(\mathrm{C})$ to Blend $\mathrm{P}$, but a small increase in coke rate from Blend M30 (C) to Blend M30. As expected, these changes are not large.

The trends obtained for Blend M20 using the conventional and new techniques are identical to those shown in Fig. 
2. The results obtained for Blends P, M20 and M30 using both the conventional and new techniques clearly show that the introduction of the annular layer of fines had an large effect on measured airflow rates and, consequently, sintering results.

\subsection{Reasons for Differences in Airflow Rates}

The difference in sintering results between the conventional and new techniques is quite contrary to early expectations. In the presence of an annular fines layer it would seem that all the air would be forced through the bed (since there is very little or no ingress of air at the walls), giving an increased rate of convective heat transfer, resulting in increased flame front speed and shorten sintering time. This reasoning is clearly incorrect because sintering occurs under a constant pre-determined suction. The fan is controlled to generate a pressure drop of $16 \mathrm{kPa}$ at the windbox, and this pressure can be maintained for the wide range of gas volumes encountered in sinter pot tests. This means that in the conventional tests, even with the ingress of air at the wall, the bottom of the sinter bed still 'sees' the full $16 \mathrm{kPa}$ pressure. In spite of the fact that applied suction and bed height are the same for the conventional and new techniques, sintering time is very much shorter for the conventional test and this requires explanation.

To understand the differences in sintering behaviour between the two techniques, it is necessary to understand the large differences in both green and sintering bed airflow rates separately. For the green bed, lower airflow rate for the new technique resulted because of:

a) no or little ingress of air at the wall-granule interface,

b) the reduction in granulated bed surface area caused by the introduction of the annular layer, and

c) the lower level of return sinter fines resulting in inferior granulation at the same mix moisture.

The decrease in granulated bed surface area caused by the introduction of the annular layer was $11.7 \%$ so airflow rates for the new technique should be lower by this same amount - if it is assumed that the annular layer is completely impervious, which is not strictly true. Table 4 shows that the decreases in green bed airflow rate for the three blends are higher than this value by around 1.6 to $3.5 \%$. This difference could be caused by the ingress of air at the wall and differences in green bed permeabilities. Even though standard granulation conditions were used and mix moistures were comparable, the two beds cannot be assumed to have similar permeabilites because they contained different levels of return fines, which were different in size distribution and porosity to the other blend component. Studies have shown that even if the blend composition was identical mix moisture is still not a good indicator of granulation efficiency because the blend components may not have the same inherent moisture content. In granulation, particles need not be fully saturated before surface water becomes available for inter-particle adhesion. ${ }^{4)}$

Table 4 shows that for both techniques the introduction of the flame front reduced airflow through the bed significantly. For the sintering bed, the decreases in sintering airflow rate for the three blends are higher than the equivalent green bed airflow values by around 4\%. During sintering, the conventional and new techniques gave different airflow
Table 4. Airflow rates obtained for the conventional and new techniques.

\begin{tabular}{|c|c|c|c|c|}
\hline & \multirow{2}{*}{$\begin{array}{l}\text { Coke addition } \\
\text { (mass } \% \text { ore } \\
\text { basis) }\end{array}$} & \multicolumn{2}{|c|}{ Airflow rate $\left(\mathrm{m}^{3} / \mathrm{h}\right)$} & \multirow{2}{*}{$\begin{array}{l}\text { Decrease in } \\
\text { airflow rate } \\
\text { caused by the } \\
\text { flame front }(\%)\end{array}$} \\
\hline & & $\begin{array}{c}\text { Green } \\
\text { bed }\end{array}$ & $\begin{array}{c}\text { Sintering } \\
\text { bed }\end{array}$ & \\
\hline Blend $\mathrm{P}(\mathrm{C})$ & 6.25 & 375 & 205 & 45.4 \\
\hline Blend P & 6.25 & 325 & 169 & 48.0 \\
\hline $\begin{array}{l}\text { Difference in airflow } \\
\text { between conventional } \\
\text { and new techniques (\%) }\end{array}$ & & 13.3 & 17.6 & \\
\hline Blend M20(C) & 6.5 & 395 & 209 & 47.1 \\
\hline Blend M20 & 6.5 & 335 & 170 & 49.2 \\
\hline $\begin{array}{l}\text { Difference in airflow } \\
\text { between conventional } \\
\text { and new techniques (\%) }\end{array}$ & & 15.2 & 18.7 & \\
\hline Blend $\mathrm{M} 30(\mathrm{C})$ & 6.75 & 405 & 205 & 49.5 \\
\hline Blend M30 & 6.75 & 345 & 166 & 51.0 \\
\hline $\begin{array}{l}\text { Difference in airflow } \\
\text { between conventional } \\
\text { and new techniques }(\%)\end{array}$ & & 14.8 & 19.0 & \\
\hline
\end{tabular}

rates because of:

a) the decrease in granulated bed surface area for the new technique caused by the introduction of the annular layer,

b) ingress of air at the wall-granule interface for the conventional technique,

c) the increased ingress of air at the wall for the conventional technique because of bed shrinkage, and

d) differences in flame front properties.

As tests using the conventional technique have a higher level of return fines in the mix, flame front temperatures will be lower for the same coke addition rate. The more permeable sintering bed has resulted in higher airflow rates, a faster flame front speed and lower sinter strength (see $\mathrm{Loo}^{4,6)}$ for a discussion of this area). The results indicated in Table 4 and Figs. 3 and 4 suggest that the decrease in sintering time is much greater than that expected for an $\sim 4 \%$ increase in airflow rates. It is most likely that increasing return fines level also decreased bed bulk density and this contributed to the observed decrease in sintering time.

The difference in flame front temperatures caused by dissimilar return fines levels is probably the major factor influencing sintering time, sinter yield and strength between the two techniques. These results reiterate the importance of the flame front properties in determining the permeability of the sintering bed. While increasing the return fines level clearly lowered flame front temperature, it is important to note that increasing sintering airflow rate will also further reduce flame front temperature. For the conventional tests the total volume of air flowing into the bed during sintering is much higher. As this air leaves the bed fully saturated at around $55^{\circ} \mathrm{C}$, more water is carried out as a vapour at $55^{\circ} \mathrm{C}$ rather than as a liquid at $55^{\circ} \mathrm{C}$. $^{4)}$ This together with the need to heat the additional air effectively lowered $T_{\mathrm{i}}$ and $T_{\mathrm{f}}$ (assuming a constant $Q$ in Fig. 2), resulting in an even more permeable bed.

\subsection{Comparison of Trends from the Two Techniques}

The results for Blends P, M20 and M30 using the conventional technique are shown in Fig. 5, while Fig. 6 shows the equivalent results using the new technique. Both techniques show that as the level of Marra Mamba ore was in- 


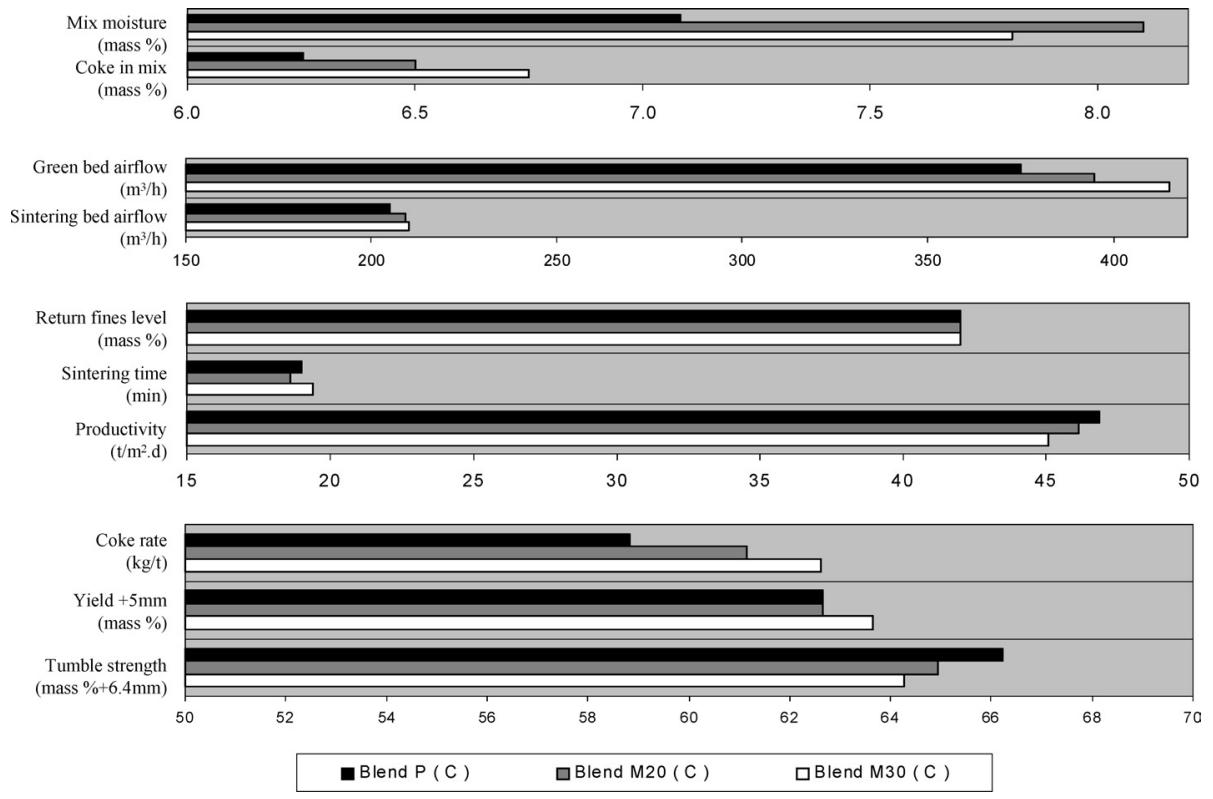

Fig. 5. Sintering results for Blend $\mathrm{P}(\mathrm{C})$, Blend $\mathrm{M} 20(\mathrm{C})$ and $\mathrm{Blend} \mathrm{M} 30(\mathrm{C})$.
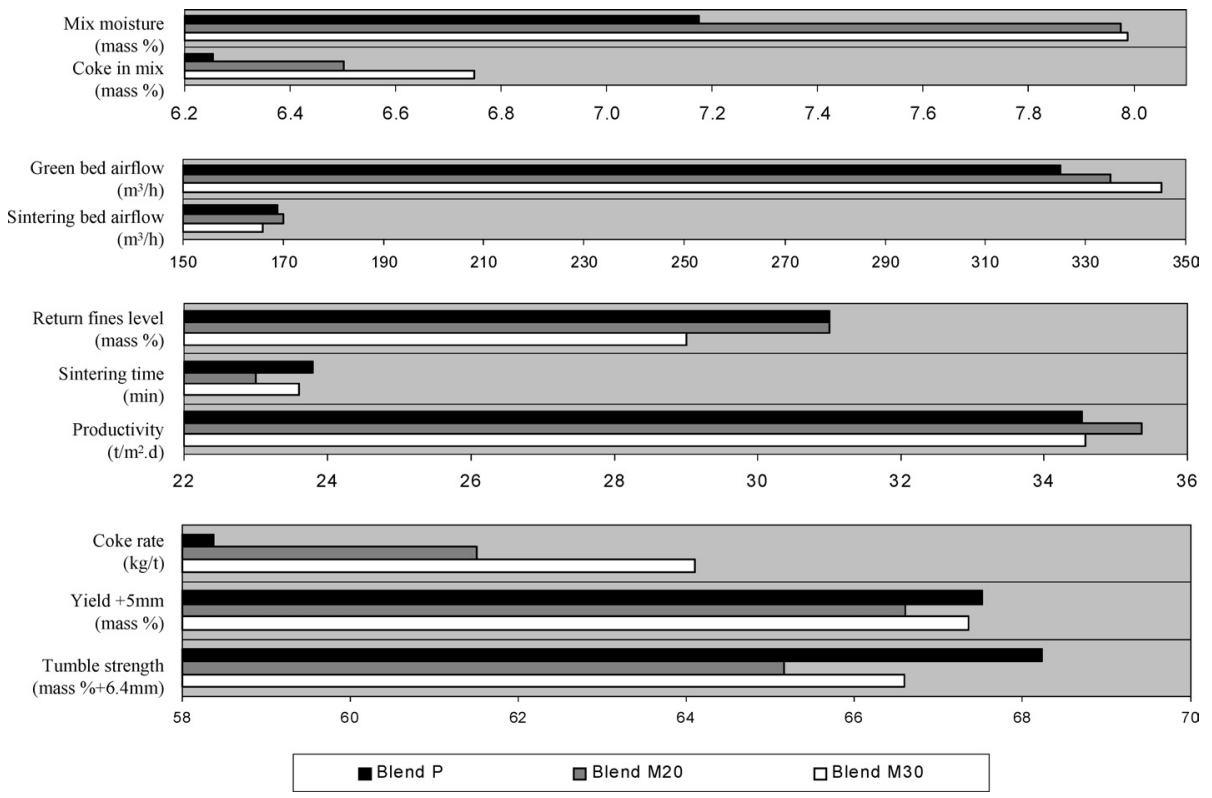

Fig. 6. Sintering results for Blend P, Blend M20 and Blend M 30 .

creased from 0 to $20 \%$, a significant increase in mix moisture was required to maintain productivity (to $\pm 1 \mathrm{t} / \mathrm{m}^{2} \cdot \mathrm{d}$ ) and sinter strength (to \pm 1 mass $\%+6.4 \mathrm{~mm}$ ).

Figure 5 shows that for the conventional technique, return fines in the sinter mix can be maintained with increasing levels of Marra Mamba ore because sinter yield from the three tests are very similar. However, to maintain sinter strength increases in coke rate were required. The sintering airflow rates and sintering time for the three blends were very similar in spite of differences in green bed airflow rates.

Figure 6 shows the results using the new technique. A slightly lower level of return fines in the sinter mix was used for Blend M30. This led to increases in flame front temperature and sintering time. The overall trend obtained for increasing Marra Mamba ore in the blend is very similar to that shown in Fig. 5. Basically, productivity can be maintained if mix moisture and coke addition are increased.
The sinter formed from Blend M20 had a lower tumble index, but Blend M30 results indicate that a stronger sinter can be produced using more coke.

The mineralogy of the sinters produced from the two techniques is given in Table 5. Generally, the conventional technique produced sinters containing slightly less magnetite and less silico-ferrite of calcium and aluminium (SFCA), confirming that higher flame front temperatures were obtained for the new technique.

\subsection{Sinter Size Distribution}

The size distributions of all the sinters produced were determined. With the exception of a few particles, which were broken manually, most of the sinter particles after stabilisation were less than $40 \mathrm{~mm}$. The stabilised sinters were screened using 40, 25, 16, 10 and $5 \mathrm{~mm}$ screens.

Figures 7 and 8 show the effect of blend composition using both the conventional and new sintering techniques. 
Table 5. Mineral of sinters formed using the conventional and new techniques.

\begin{tabular}{|l|c|c|c|c|c|c|}
\hline \multirow{2}{*}{ Minerals/phases } & \multicolumn{7}{|c|}{ Blends } \\
\cline { 2 - 7 } & $\mathbf{P}(\mathbf{C})$ & $\mathbf{P}$ & $\mathbf{M 2 0}(\mathbf{C})$ & $\mathbf{M 2 0}$ & $\mathbf{M 3 0}(\mathbf{C})$ & M30 \\
\hline Primary hematite & 18.6 & 19.0 & 12.8 & 14.6 & 12.6 & 13.6 \\
\hline Secondary hematite & 21.6 & 23.2 & 23.2 & 19.8 & 15.2 & 18.2 \\
\hline Magnetite & 13.6 & 17.6 & 18.6 & 23.0 & 22.8 & 22.0 \\
\hline SFCA & 32.6 & 27.8 & 30.4 & 28.4 & 33.2 & 31.2 \\
\hline Glass & 2.6 & 1.2 & 4.6 & 5.6 & 4.0 & 3.2 \\
\hline Dicalcium silicate & 7.8 & 9.2 & 7.4 & 6.8 & 9.8 & 9.6 \\
\hline Others & 3.2 & 2.0 & 3.0 & 1.8 & 2.4 & 2.2 \\
\hline
\end{tabular}

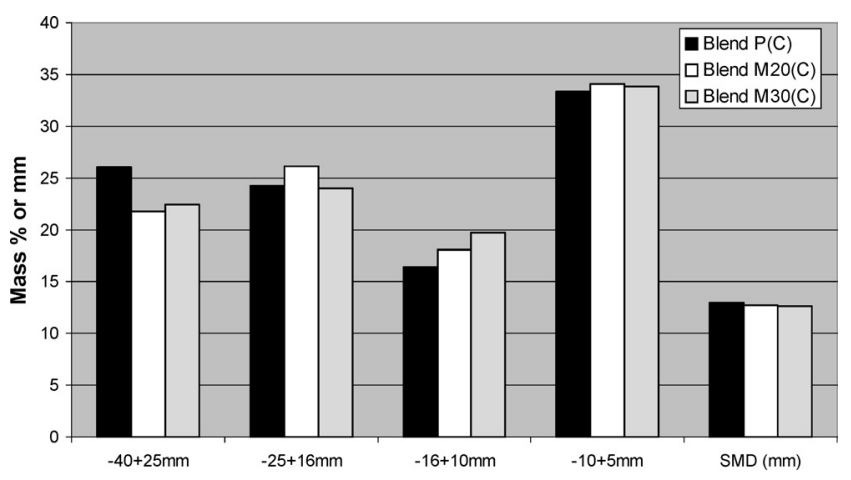

Fig. 7. Size distribution and Sauter Mean Diameter (SMD) of sinters produced from the three blends using the conventional technique.

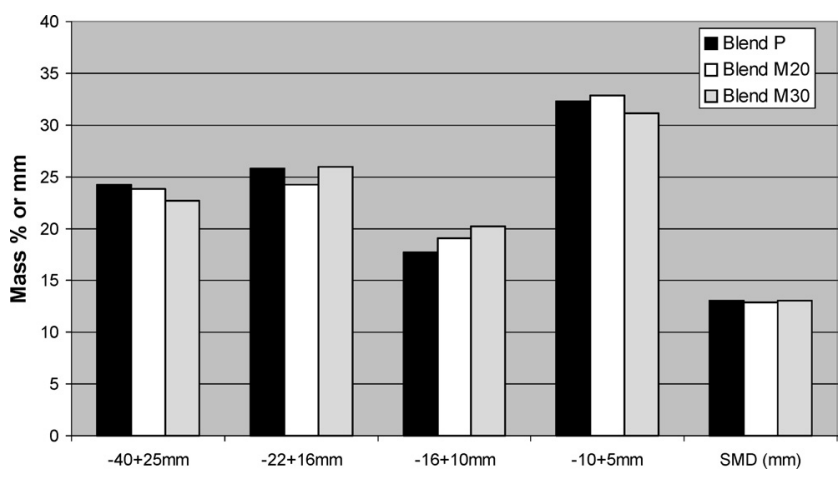

Fig. 8. Size distribution and Sauter Mean Diameter (SMD) of sinters produced from the three blends using the new technique.

Both techniques gave very similar sinter size distributions and Sauter Mean Diameters (SMD). This is an unexpected finding because tumble strengths were generally higher for sinters produced using the new technique. A possible explanation could be that only the stronger sinter particles survive the shatter treatment, and that the size distribution of these stabilized particles are more dependent on the forces encountered during the shatter treatment than on sintering conditions and ore blend composition.

\section{Discussions and Conclusions}

The results obtained in this study show very clearly that sintering is very complex process, controlled by several parameters that are interdependent. Although changing an ore blend can have a very profound effect on sintering performance and sinter strength, the link between the cause and the effect is not direct, as demonstrated in this study. To effectively improve sintering performance or formulate coun- termeasures to overcome deterioration in the sintering performance indicators, these links have to be identified and understood.

This study has shown that pot tests can only give useful information if they are carried out meaningfully. However, results are highly dependent on whether the pot was sealed at the walls using an annular layer of fine ore. With the annular layer, return fines level was much lower and this had a significant effect on the sintering process. At some centres, sinter pot tests are carried out at a fixed level of return fines; this is incorrect because yield or the level of return fines generation is a function of ore blend and sintering conditions - both of which also influence each other.

The results in this study would suggest that the performance of a sinter machine is somewhere between that of the new and conventional. It is probably closer to the conventional technique. Although the ratio of wall area to mass of sinter produced is comparatively small on a sinter machine, cracks that develop in a sintering bed as it moves towards the discharge end of the strand will affect the process in very much the same way as the sinter pot wall. For research purposes, especially to understand the fundamental factors driving sinter plant performance, the new technique should be used. With the elimination of return fines generation from around the pot walls, fines generated from the sintered bed structure will be the only contributor to yield. For comparative purposes, there is a need to quantify the theoretical yield obtainable from different ore blends under defined sintering conditions; if required, these values can be modified to take into consideration the fact that sinter machines have varying levels of cracking and air ingress at the sideplates.

This study has shown that it is possible to sinter blends containing up to 80 mass\% Australian goethitic ore at acceptable productivity and sinter strength. In this study, many of the observed changes in productivity and sinter strength could be traced back to changes in flame front properties, especially its temperature. Flame front temperature has a very large impact on sintering time and productivity because of its strong influence on flame front permeability. In this study, even though coke addition level (on ore basis) was not altered, the increased level of return fines in the sinter mix for the conventional tests meant that the mass percent coke per unit mass of sinter mix decreased and this reduced flame front temperature. The ingress of air at the walls for the conventional tests also meant that more heat was carried out of the bed and this reduced flame front temperature further. Results show that reducing flame front temperatures is very beneficial to productivity because the resistance of the flame front to airflow is a function of gas velocity to the power of three. Raising flame front temperature greatly increases airflow resistance and leads to increased sintering time and reduced productivity.

Many plants have observed that sinter plant productivity and sinter strength can be maintained without increasing coke rate when significant levels (up to 30 mass $\%$ ) of pisolite ore is introduced into the blend. To maintain sinter plant productivity, it is obvious that sintering time must reduce since pisolite ore has lower bulk density and a sinter machine operates on a fixed material volume basis (see Ref. 4) for a full discussion). With pisolite ore in the blend, the 
flame front speed will increase because pisolite ore has lower thermal capacity and because of reduced flame front temperature - a direct result of additional energy required to dehydrate goethites and remove the addition water used in granulation (refer to Fig. 2 and Ref. 4) for more details). Lowering flame front temperature and increasing flame front speed reduces the heat available during the melt formation period and, in theory, this should lead to a deterioration in sinter strength; in practice, sinter strength could be maintained because pisolite ore reacts very rapidly and sufficient melt is generated as the flame front passes through. ${ }^{4)}$ Clearly, the ability of goethites to form sufficient melt at lower flame front temperature is a positive contribution towards achieving high sinter plant productivity.

\section{Acknowledgements}

The authors gratefully acknowledge the financial support given BHP Billiton Iron Ore.

\section{REFERENCES}

1) C. E. Loo and J. Leaney: Trans. Inst. Min. Metall. C, 111 (2002), C11.

2) C. E. Loo and M. F. Hutchens: ISIJ Int., 43 (2003), 630.

3) C. E. Loo: Proc. 2nd Int. Cong. Sci. \& Tech. Ironmaking/57th Ironmaking Conf., ISS, Warrendale, PA, (1998), 1299.

4) C. E. Loo: ISIJ Int., 45 (2005), 436.

5) C. E. Loo, L. Mackey and B. M. England: Trans. Inst. Min. Metall. C, 105 (1996), C151.

6) C. E. Loo: Trans. Inst. Min. Metall. C, 109 (2000), C11.

7) C. E. Loo and L. T. Matthews: Trans. Inst. Min. Metall. C, 101 (1992), C105. 